Tersedia online di: http://ejournal-balitbang.kkp.go.id/index.php/bawal
e-mail:bawal.puslitbangkan@ gmail.com
BAWAL wIDYA RISET PERIKANAN TANGKAP
Volume 9 Nomor 1 April 2017
p-ISSN: 1907-8226
e-ISSN: 2502-6410
BAWALAL
Nomor Akreditasi: 620/AU2/P2MI-LIPI/03/2015

\title{
PARAMETER POPULASI UDANG DOGOL (Metapenaeus ensis) DAN UDANG WINDU (Penaeus monodon) DI LAUT ARAFURA
}

\section{POPULATION PARAMETERS of ENDEAVOUR SHRIMP (Metapenaeus ensis) and BLACK TIGER PRAWN (Penaeus monodon) IN ARAFURA SEA}

\author{
Ali Suman*1, Budi Iskandar Prisantoso ${ }^{2}$, dan Duranta D. Kembaren ${ }^{1}$ \\ ${ }^{1}$ Balai Penelitian Perikanan Laut, Komp. PPS Nizam Zachman, Jalan Muara Baru Ujung, Penjaringan, \\ Jakarta Utara 14440, Indonesia \\ ${ }^{2}$ Pusat Riset Perikanan, Jalan Pasir Putih II, Ancol Timur Jakarta Utara, 14430, Indonesia \\ Teregistrasi I tanggal: 02 Juni 2016; Diterima setelah perbaikan tanggal: 07 Juni 2017; \\ Disetujui terbit tanggal: 20 Juli 2017
}

\begin{abstract}
ABSTRAK
Sumber daya udang di perairan Arafura merupakan salah satu modal menuju kemakmuran bagi bangsa, apabila dikelola secara berkelanjutan. Kajian dinamika populasi udang, merupakan salah satu dasar utama dalam merumuskan pengelolaan tersebut menuju pemanfaatan sumber daya yang lestari. Tujuan penelitian ini adalah untuk mengetahui dinamika populasi udang dogol dan udang windu di perairan Arafura dan sekitarnya. Penelitian dilakukan dari bulan Januari 2013 sampai dengan Nopember 2013 dan analisis dilakukan dengan menggunakan FAO-ICLARM Fisheris Stok Assessment Tools (FISAT). Hasil penelitian menunjukkan bahwa laju pertumbuhan (K) udang dogol sebagai 1,33 per tahun dan panjang karapas maksimum (L) sebagai 52,0 mm. Untuk udang windu didapatkan nilai $\mathrm{K}$ sebagai 1,45 per tahun dan nilai L sebagai $62,5 \mathrm{~mm}$. Laju kematian total (Z) udang dogol sebagai 4,79 per tahun, laju kematian karena penangkapan (F) dan laju kematian alami (M) masing-masing 2,91 per tahun dan 1,88 per tahun. Untuk udang windu didapatkan nilai $\mathrm{Z}$ sebagai 6,13 per tahun, nilai $\mathrm{F}$ dan nilai M masing-masing 4,24 dan 1,89 per tahun. Laju pengusahaan (E) udang dogol 0,61 per tahun dan nilai $\mathrm{E}$ udang windu sebagai 0,69 per tahun. Tingkat pemanfaatan sudah berada dalam tahapan overfishing dan perlu dilakukan pengurangan jumlah upaya $22 \%$ untuk udang dogol dan $38 \%$ untuk udang windu.
\end{abstract}

Kata Kunci: Parameter populasi; udang dogol; udang windu; Laut Arafura

\begin{abstract}
Shrimp resources within Arafura Sea if under sustainably management it would contribute a significant role as a source of nation welfare. Scientific advice on population dynamic are required as an input to support an apropriate fisheries management. The purpose of the study was to identify population parameters of the endeavour shrimp and tiger shrimp in Arafura Sea. Study on the population dynamic of endeavour shrimp and king tiger prawn were conducted in Arafura Sea based on data collected during period of survey, January 2013 to November 2013. The analysis is using the FAO-ICLAM Fisheries Stock Assessment Tools (FiSAT). Result showed that the growth parameter of endeavour shrimp was 1.33/year with maximum carapace length $(L \infty)$ of $52.0 \mathrm{~mm}$. Instantenous total mortality $(Z)$ and natural mortality $(M)$ were $4.79 /$ year and 1.88/year, respectively. While fishing mortality $(F)$ and exploitation rate $(E)$ of endeavour shrimp respectively were 2.91/year and $0.61 /$ year. The growth parameter of king tiger prawn was 1.45/year with maximum carapace length $(L)$ of $62.5 \mathrm{~mm}$. Instantenous total mortality $(Z)$ and natural mortality $(M)$ were $6.13 /$ year and 1.89/year, respectively. While fishing mortality $(F)$ and exploitation rate $(E)$ of king tiger prawn respectively were 4.24/year and 0.69/year. The exploitation rate of endeavour shrimp and king tiger prawn in Arafura Sea was overfishing. It was, therefore, recommended that fishing effort of $22 \%$ the endeavour shrimp and $38 \%$ king tiger prawn in that waters should be reduced in the next year.
\end{abstract}

Keywords: Population parameters; endeavour shrimp; tiger shrimp; Arafura Sea 


\section{PENDAHULUAN}

Laut Arafura merupakan daerah penangkapan udang yang paling potensial di Indonesia. Penangkapan udang secara komersial di Laut Arafura dimulai pada awal tahun 1970-an, yaitu sesudah diperkenalkannya usaha penangkapan udang menggunakan kapal trawl udang ganda. Sejarah perkembangan trawl di Indonesia dimulai sejak tahun 1960-an sejalan dengan makin meningkatnya pasaran udang di tingkat dunia (Naamin, 1978; 1984; Tirtadanu \& Tri Ernawati, 2016). Kemudian trawl berkembang pesat di Indonesia dan menjadi alat tangkap udang yang efektif dan efisien. Adanya konflik pemanfatan antara nelayan tradisional dengan nelayan trawl, maka diterbitkan Keputusan Presiden No. 39/1980 tentang penghapusan trawl kecuali di Laut Arafura. Selanjutnya penggunaan trawl di Laut Arafura diatur melalui Keputusan Presiden No. 85 Tahun 1983 tentang penggunaan Pukat Udang di Indonesia Timur yang diijinkan pada batas koordinat $130^{\circ} \mathrm{BT}$ ke arah timur pada isobath $10 \mathrm{~m}$. Jaring trawl udang (pukat udang) yang digunakan di Laut Arafura paling lambat pada akhir tahun 1983 harus sudah menggunakan TED (Turtle Excluder Device). Alat pemisah ikan tersebut kemudian diubah namanya menjadi BED (Bycatch Excluder Device). Armada pukat udang tipe "double-rig trawler" lebih efektif untuk menangkap udang dibandingkan dengan tipe "stern trawler" (Naamin, 1984).

Perkembangan pesat dan berlanjut dari kapasitas penangkapan armada perikanan pukat udang di Laut Arafura telah berdampak pada penurunan kelimpahan stok udang, serta peningkatan ancaman terhadap kelestariannya. Hasil evaluasi perkembangan perikanan udang di Laut Arafura menunjukkan bahwa stok udang di daerah penangkapan tersebut sudah dimanfaatkan berlebih, melebihi daya dukungnya (Badrudin, 2002). Hasil kajian ulang yang dilakukan oleh Purwanto (2010) dengan memperhitungkan kegiatan penangkapan udang secara illegal, menunjukan bahwa tingkat pemanfaatan udang di Laut Arafura pada tahun 2004 - 2008 secara biologis tidak lagi berlebih, walaupun secara ekonomis belum mencapai tingkat optimal (Purwanto, 2010).

Dalam rangka memperbarui informasi tentang status stok udang di Laut Arafura, maka tulisan ini akan membahas dinamika populasi udang dogol dan udang windu di perairan ini. Diharapkan hasil penelitian ini dapat digunakan sebagai bahan masukan untuk tujuan pengelolaan dan dasar bagi pengkajian selanjutnya.

\section{BAHANDANMETODE}

Penelitian dilakukan bulan dari Januari 2013 sampai dengan Nopember 2013 di perairan Arafura dan sekitarnya. Pengumpulan data dilakukan dengan bantuan enumerator di Pelabuhan Perikanan Nusantara (PPN) Ambon.
Pengamatan biometrik udang meliputi panjang karapas, berat individu dan jenis kelamin. Panjang karapas diukur dengan menggunakan jangka sorong (tingkat ketelitian 0,01 mm). Data panjang karapas yang diperoleh kemudian ditabulasikan dalam tabel distribusi frekuensi panjang karapas dengan interval $2 \mathrm{~mm}$. Data frekuensi panjang karapas tersebut selanjutnya digunakan untuk mengestimasi parameter populasi udang dogol dan udang windu.

Pertumbuhan udang dianalisis menggunakan model pertumbuhan von Bertalanffy (Sparre \& Venema, 1998) dengan persamaan sebagai berikut:

$\mathrm{Lt}=\mathrm{Loo}\left(1-\mathrm{e}^{-\mathrm{K}(\mathrm{t}-\mathrm{t})}\right)$

Penentuan panjang karapas asimtotik $\left(\mathrm{L}^{\infty}\right)$ dan koefisien pertumbuhan (K) diduga menggunakan program Electronic Length Frequency Analysis (ELEFAN) yang dikemas dalam perangkat lunak FiSAT II (Gayalino et al., 2005). Metode ELEFAN ini adalah penyempurnaan dan pengintegrasian teknik pendugaan pertumbuhan antara metode pergeseran modus penyebaran frekuensi panjang dan metode Petersen (Sparre \& Venema, 1992).

Laju mortalitas alamiah (M) diduga dengan persamaan empiris Pauly (1983) dengan menggunakan data rata-rata suhu permukaan perairan laut Arafura tahunan (T) yaitu $29^{\circ} \mathrm{C}$, yaitu:

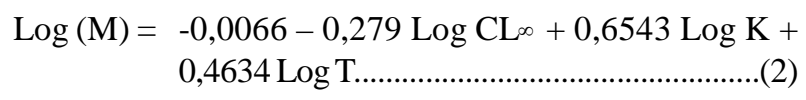

Laju kematian total ( $\mathrm{Z}$ ) diduga dengan metode kurva hasil tangkapan (catch curve) yang merupakan slope (b) antara Ln N/t dengan umur relatif sesuai dengan rumus Pauly (1980) sebagai berikut:

$\operatorname{Ln} N / t=a-Z t$

dimana:

$\mathrm{N}$ : banyaknya udang pada waktu $\mathrm{t}$

$\mathrm{t}$ : waktu yang diperlukan untuk tumbuh suatu kelas panjang

a : hasil tangkapan yang dikonversikan terhadap panjang

Mortalitas penangkapan (F) dan laju eksploitasi (E) dihitung dengan rumus (Pauly, 1983):

$\mathrm{F}=\mathrm{Z}-\mathrm{M}$ dan $\mathrm{E}=\mathrm{F} / \mathrm{Z}$

Analisis data untuk dinamika populasi tersebut digunakan program FISAT (Gayanilo et al., 1993; Sparre \& Venema, 1998; Pauly, 1980). 


\section{HASIL DAN BAHASAN \\ Hasil}

\section{Parameter Pertumbuhan dan Laju Kematian}

Pada dasarnya program ELEFAN digunakan untuk menginterpretasikan data frekuensi panjang karapas dengan cara melacak pergeseran modus sebaran frekuensi panjang karapas dalam suatu urutan waktu yang dicocokkan dengan kurva von Bertalanffy. Kurva yang melalui modus paling banyak akan menggambarkan pola pertumbuhan (Sparre \& Venema, 1992).
Dengan merunut data frekuensi panjang karapas dari bulan ke bulan maka diperoleh laju pertumbuahn (K) udang dogol di perairan Arafura dan sekitarnya yaitu 1,33 per tahun dan panjang karapas maksimum $(\mathrm{L} \infty)$ yaitu $52,0 \mathrm{~mm}$ (Gambar 1). Dengan memasukan nilai tersebut maka diperoleh persamaan pertumbuhan von Bertalanffy untuk udang dogol di perairan Arafura dan sekitarnya adalah: $\mathbf{L t}=\mathbf{5 2 , 0}\left[1-\mathrm{e}^{-1,33(t+0,003)}\right]$

Dengan cara yang sama diperolah laju pertumbuhan (K) udang windu 1,45 per tahun dan panjang karapas maksimum (L) sebagai 62,5 mm (Gambar 2). Persamaan pertumbuhan von Bertalanffy untuk udang windu di perairan Arafura adalah: $\mathbf{L t}=\mathbf{6 2 , 5}\left[1-\mathrm{e}^{-\mathbf{1 , 4 5 ( t + 0 , 0 0 3 )}}\right]$

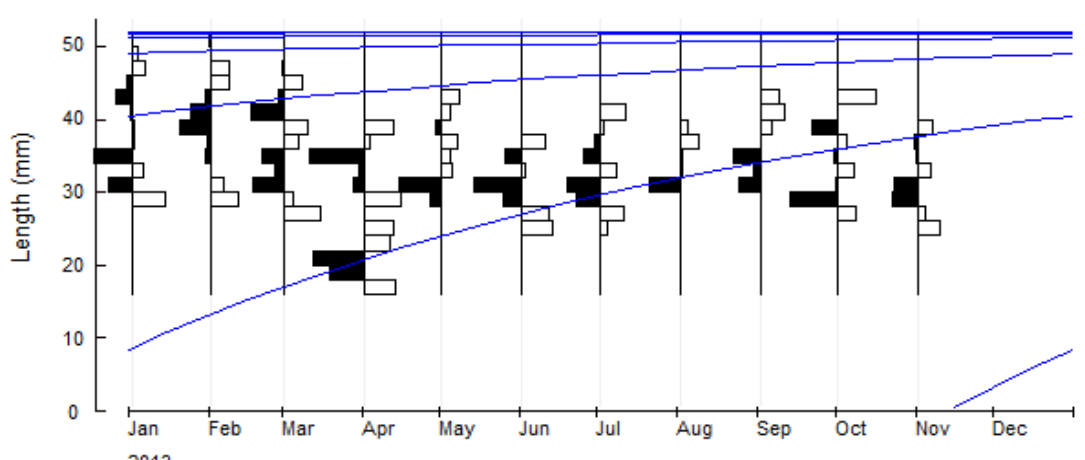

Gambar 1. Distribusi panjang karapas bulanan dan kurva pertumbuhan udang dogol (M. ensis) yang dianalisis dengan program ELEFAN.

Figure 1. Carapace length distribution by month of endeavour shrimp (M. ensis) and growth curves fitted by ELEFAN.

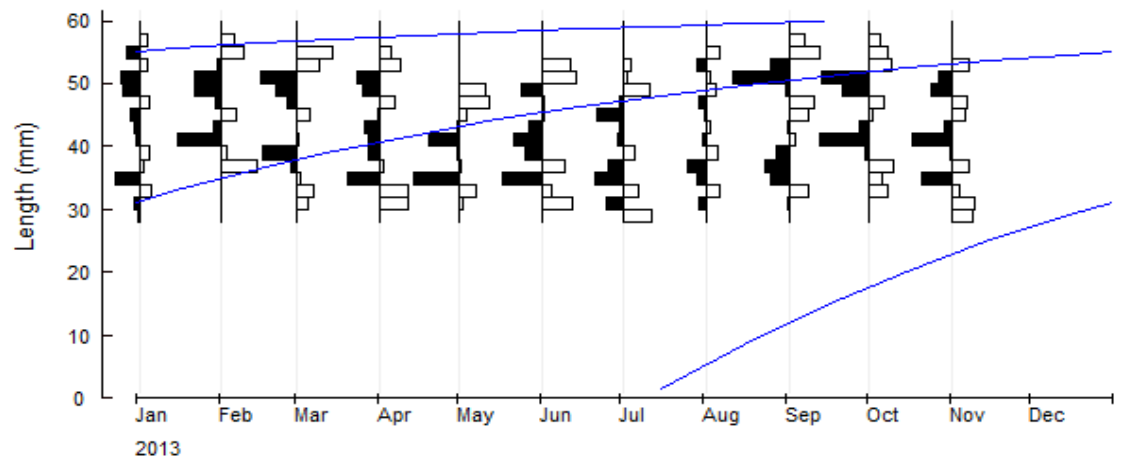

Gambar2. Distribusi panjang karapas bulanan dan kurva pertumbuhan udang windu (P. monodon) yang dianalisis dengan program ELEFAN.

Figure 2. Carapace length distribution of tiger prawn (P. monodon) and growth curve fitted by ELEFAN.

Parameter pertumbuhan yang telah dihitung digunakan sebagai bahan masukan untuk membuat kurva hasil tangkap. Diperoleh nilai dugaan $\mathrm{Z}$ untuk udang dogol sebagai 4,79 per tahun (Gambar 3).

Nilai dugaan laju kematian alamiah (M) dihitung dengan menggunakan persamaan Pauly (1980) dan diperoleh nilai $\mathrm{M}$ untuk udang dogol sebesar 1,88 per tahun. Nilai dugaan laju kematian karena penangkapan
(F) udang dogol dihitung sesuai rumus : $\mathrm{F}=\mathrm{Z}-\mathrm{M}$ dan diperoleh hasil sebesar 2,91 per tahun. Dengan cara yang sama diperoleh nilai laju kematian total (Z) udang windu sebagai 6,13 per tahun (Gambar 4). Selanjutnya dengan menggunakan persamaan empiris Pauly (1980) di peroleh nilai laju kematian alamiah (M) untuk udang windu sebagai 1,89 per tahun dan dengan menggunakan rumus: $\mathrm{F}=\mathrm{Z}-\mathrm{M}$, diperoleh nilai $F$ udang windu sebagai 4,24 per tahun. 
Length-Converted Catch Curve

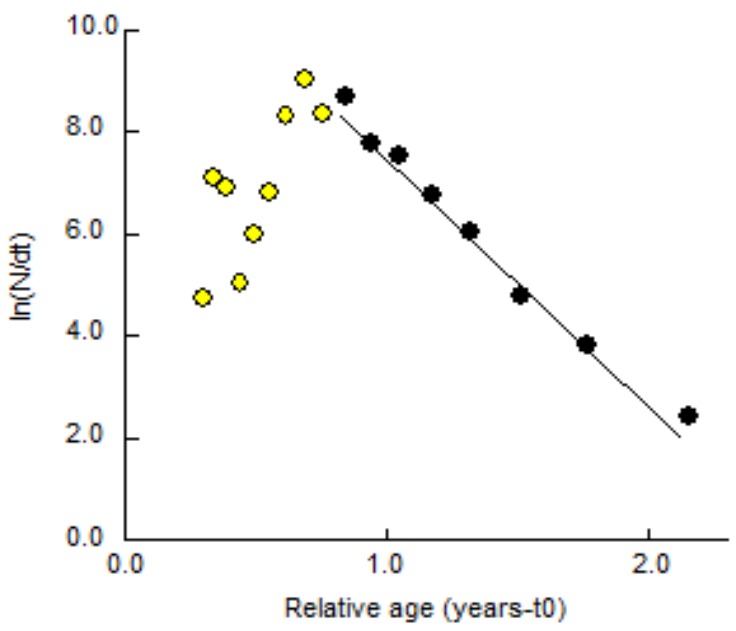

Gambar3. Nilai Z sebagai slope hasil tangkapan udang dogol (M. ensis).

Figure 3. The value of total mortality (Z) as length converted catch curve of endeavour shrimp (M. ensis).

\section{Laju Pengusahaan}

Dengan menggunakan nilai $\mathrm{F}$ sebagai parameter kematian karena penangkapan dan nilai $\mathrm{Z}$ sebagai parameter kematian total diperoleh nilai laju pengusahaan (E) udang dogol sebesar 0,61 per tahun dan udang windu yaitu 0,69 per tahun. Nilai E ini menggambarkan tingkat pemanfaatan udang dogol dan windu yang sudah melebihi potensi lestarinya.

\section{Bahasan}

Nilai K udang dogol dan udang windu yang lebih besar dari satu menunjukkan bahwa udang ini mempunyai pertumbuhan yang cepat (Gulland, 1983; Naamin, 1984). Cepatnya pertumbuhan dan pendeknya umur udang menunjukkan bahwa laju kematiannya cukup tinggi. Hal ini memberikan peringatan kepada kita agar memperhatikan pemanfaatannya secara berkelanjutan. Sehubungan dengan umur, laju pertumbuhan dan kematian ini yang perlu diperhatikan adalah: waktu yang tepat untuk menangkapnya, baik ditinjau dari sumber dayanya sendiri maupun dari segi ekonominya. Kalau terlambat menangkap maka udang ini akan mati percuma, sedangkan kalau terlalu cepat ditangkap secara ekonomi dan kelestarian sumber daya juga kurang menguntungkan.

Laju pertumbuhan (K) udang dogol di perairan Arafura lebih kecil bila dibandingkan dengan laju pertumbuhan udang dogol di perairan Cilacap yaitu 1,52 per tahun untuk udang dogol betina dan 1,49 per tahun untuk udang dogol jantan (Suman, 2004; El Fakhri, 2015; Kembaren \& Ernawati, 2015), tetapi lebih besar bila dibandingkan dengan nilai $\mathrm{K}$
Length-Converted Catch Curve

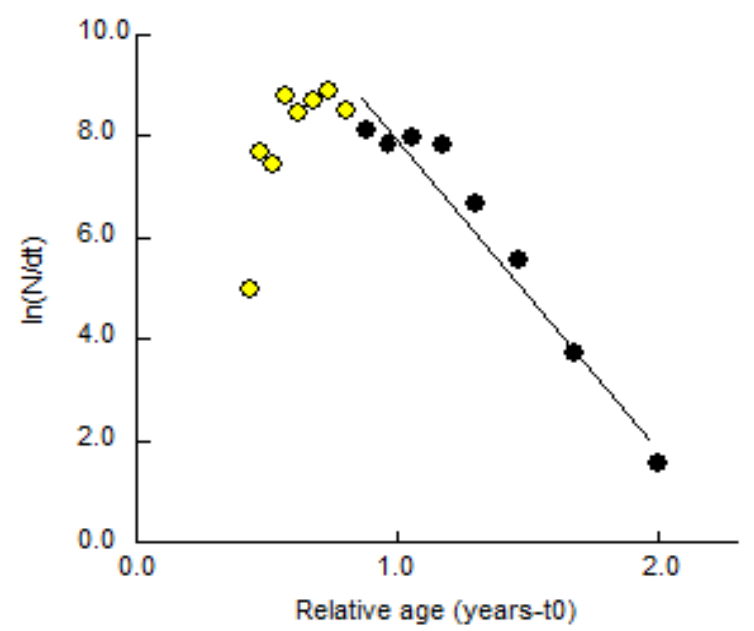

Gambar4. Nilai Z sebagai slope hasil tangkapan udang windu (P. monodon).

Figure 4. The value of total mortality $(Z)$ as length converted catch curve of tiger shrimp ( $P$. monodon).

udang dogol (Metapenaeus affinis) di perairan Versoba, India yang sebesar 1,20 per tahun (Pauly et al., 1984). Fenomena yang sama ditemukan pada udang windu, dimana nilai K udang windu di Laut Arafura terlihat lebih kecil bila dibandingkan nilai $\mathrm{K}$ udang windu di perairan Selat Madura yang sebesar 1,5 per tahun (Setyohadi, 2010), serta di perairan Tarakan sebesar 1,6 per tahun (Kembaren $\&$ Nurdin, 2013). Fenomena yang berbeda apabila dibandingkan dengan nilai K udang widu di perairan Aceh Timur yang hanya 1,1 per tahun (Hedianto et al., 2016), terlihat nilai $\mathrm{K}$ udang windu di Laut Arafura lebih besar. Hal ini menunjukkan bahwa pertumbuhan udang dogol Laut Arafura lebih lambat bila dibandingkan dengan pertumbuhan udang dogol di perairan Cilacap dan Versoba. Fenomena yang sama ditemukan pada udang windu menunjukkan pertumbuhan yang lebih lambat bila dibandingkan dengan di perairan Selat Madura dan Tarakan. Fenomena lain didapatkan untuk perairan Aceh Timur, terlihat pertumbuhan di perairan ini lebih lambat bila dibandingkan dengan pertumbuhan udang windu di laut Arafura. Adanya perbedaan laju pertumbuhan udang ini pada berbagai perairan kemungkinan dipengaruhi oleh ketersediaan makanan dan kondisi lingkungan (Sparre \& Venema, 1998).

Laju kematian total (Z) udang dogol di Laut Arafura lebih rendah dari perairan Cilacap yang berkisar 6,71-8,68 per tahun (Suman, 2004), sementara nilai Z untuk udang windu terlihat lebih rendah bila dibandingkan dengan perairan Selat Madura, Tarakan dan Aceh Timur. Nilai Z di perairan Selat Madura berkisar antara 3,28-3,78 per tahun, di perairan Tarakan sebesar 4,17 pert tahun dan di perairan Aceh Timur sebesar 4,09 per tahun (Setyohadi, 2010; 
Kembaren \& Nurdin, 2013; Hedianto et al., 2016). Tinggi rendahnya nilai $\mathrm{Z}$ ini sangat dipengaruhi oleh tekanan penangkapan. Secara keseluruhan apabila dibandingkan dengan perairan lainnya, terlihat tekanan penangkapan udang dogol lebih rendah di Laut Arafura, tetapi sangat intensif untuk udang windu. Hal ini berkaitan dengan tujuan utama penangkapan udang di Laut Arafura adalah udang windu, sehingga eksploitasi terhadap jenis ini dilakukan secara terus menerus dengan intensitas yang lebih tinggi bila dibandingkan jenis udang lainnya seperti udang dogol (Hargiyanto et al., 2015).

Laju kematian karena penangkapan (F) udang dogol di laut Arafura terlihat lebih rendah bila dibandingkan dengan nilai F di perairan Cilacap (Suman, 2004), sementara untuk udang windu terlihat lebih tinggi bila dibandingkan dengan perairan Selat Madura, Tarakan dan Aceh Timur (Setyohadi, 2010; Kembaren \& Nurdin, 2013; Hedianto et al., 2016). Fenomena ini sejalan dengan nilai $Z$ yang sangat dipengaruhi oleh nilai $\mathrm{F}$, yang menunjukkan bahwa tekanan penangkapan untuk udang dogol di Laut Arafura lebih rendah, tetapi sangat tinggi untuk udang windu. Hal ini berkaitan dengan harga udang windu yang jauh lebih tinggi, sehingga menjadi komoditas yang paling dicari dalam usaha penangkapan udang di Laut Arafura dan menyebabkan upaya penangkapannya sangat tinggi. Analisis selanjutnya menunjukkan laju kematian alamiah (M) udang dogol lebih rendah di Laut Arafura dibanding perairan Cilacap, sementara untuk udang windu terlihat lebih tinggi bila dibandingkan perairan Aceh Timur dan Selat Madura, tetapi lebih rendah bila dibandingkan dengan perairan Tarakan. Hal ini menunjukkan bahwa daya dukung perairan Laut Arafura lebih baik dari perairan Cilacap untuk udang dogol, sementara untuk udang windu terlihat daya dukung Laut Arafura lebih baik dibanding perairan Tarakan, namun daya dukung perairan Aceh Timur dan Selat Madura masih lebih baik.

Selanjutnya dengan menggunakan rumus laju pengusahaan $(E)=F / Z$, diperoleh nilai $E$ udang dogol di Laut Arafura sebagai 0,61/tahun dan untuk udang windu sebesar 0,69/tahun. Berdasarkan kriteria dari Pauly et al. (1984), nilai E ini menunjukkan bahwa tingkat pemanfaatan sumber daya udang dogol dan udang windu di Laut Arafura sudah berada pada tahapan yang jenuh serta kondisi pemanfaatan yang demikian akan mengancam kelestarian sumberdayanya. Nilai E udang dogol dan udang windu di atas 0,5 per tahun dan hal ini menunjukkan telah terjadi kelebihan upaya penangkapan (overfishing). Untuk udang dogol terlihat terjadi kelebihan upaya sebesar $22 \%$ dari upaya yang ada saat ini dan untuk udang windu terjadi kelebihan upaya sekitar $38 \%$. Agar pemanfaatan sumber daya udang dogol dan udang windu berada dalam yang lestari di Laut Arafura maka harus mengurangi upaya sekitar $22 \%$ untuk udang dogol dan $38 \%$ untuk udang windu dari kondisi upaya saat ini.

\section{KESIMPULAN}

Laju pertumbuhan udang dogol (Metapeneus ensis) dan udang windu (Penaeus monodon) di Laut Arafura tergolong cepat, sementara laju kematiannya termasuk tinggi. Tingkat pemanfaatan kedua jenis tersebut sudah berada dalam tahapan overfishing dan dalam jangka panjang akan mengarah pada penurunan stok. Agar sumber daya udang dogol dan udang windu berada dalam tahapan yang lestari, maka harus dilakukan pengurangan upaya sekitar $22 \%$ untuk udang dogol dan $38 \%$ untuk udang windu.

\section{PERSANTUNAN}

Tulisan berjudul "Parameter Populasi Udang Dogol (Metapenaeus ensis) dan Udang Windu (Penaeus Monodon) di Laut Arafura " merupakan hasil penelitian kami pada kegiatan penelitian bulan Januari-Nopember di Laut Arafura pada Tahun 2013. Peneliti mengucapkan terima kasih kepada Kepala Balai Penelitian Perikanan Laut, serta kepada semua pihak yang telah membantu dalam pembuatan tulisan.

\section{DAFTAR PUSTAKA}

Badrudin, Sumiono, B., \& Wirdaningsih, N. (2002). Laju tangkap, hasil tangkapan maksimum (MSY) dan upaya optimum perikanan udang di Perairan Laut Arafura. $J$. Pen. Perik. Indonesia. Edisi Sumber Daya dan Penangkapan. 8(4), 23-29.

El Fakhri, H. (2015). Dinamika populasi udang dogol (Metapenaeus ensis de Haan) dan optimasi pemanfaatannya di perairan Cilacap dan sekitarnya. Thesis Jurusan Kelautan, FMIPA, Universitas Indonesia, Depok

Gayanilo, F. C. Jr., Sparre, P., \& Pauly, D. (2005). FAOCLARM Stock Assessment Tools II (FiSAT II) (p. 168). Revised version.User's guide. FAO Computerized Information Series (Fisheries). No. 8, Revised version. FAO Rome.

Gayanilo, F.C. Jr, Sparre, P., \& Pauly, D. (1993). The FISAT user's guide. FAO computerized information series fisheries. ICLARM - DIFMAR.

Gulland, J.A. (1983). Fish Stock Assessment. A manual of basic methods. John Wiley \& Sons, Chicester.

Hargiyanto, I.T, Anggawangsa R.F., \& Sumiono B, (2015). Sebaran spacio-temporal ukuran dan densitas udang jerbung (Penaeus merguiensis de Mann, 1907) di sub area Dolak, Laut Arafura (WPP-NRI 718). J.Lit.Perikan.Ind. 21(4), 261-269. 
Hedianto, D.A., Suryandari, A., \& Tjahjo, D.W. (2016). Dinamika populasi dan status pemanfaatan udang Penaeus monodon di perairan Aceh Timur, Propinsi Aceh. J.Lit.Perik. Ind. 22(2), 71 - 82.

Kembaren, D.D., \& Nurdin, E. (2013). Dinamika populasi dan tingkat pemanfaatan udang windu (Penaeus monodon) di perairan Tarakan, Kalimantan Timur. J.Lit.Perik.Ind. 19(4), 221-226.

Kembaren, D.D., \& Ernawati, T. (2015). Dinamika populasi dan estimasi ratio potensi pemijahan udang jerbung (Penaeus merguiensis de Mann, 1907) di perairan teluk Cendrawasih dan sekitarnya, Papua. J.Lit.Perikan.Ind. 21(3), 201-210.

Naamin, N. (1978). Perkembangan perikanan udang di Indonesia. Prosiding Seminar Ke II Perikanan Udang, 55-65.

Naamin, N. (1984). Dinamika populasi udang jerbung (Penaeus merguiensis de Man) di perairan Arafura dan alternative pengelolaannya. Disertasi Doktor. Fakultas Pasca Sarjana, IPB Bogor

Pauly, D. (1980). A selection of a simple methods for the assessment of tropical fish stocks. FAO Fish. Circ. FIRM/C 729, Roma, 54.

Pauly, D. (1983). Some Simple Methods for the Assessment of Tropical Fish Stocks. FAO Fisheries Technical Paper, (254), 52.
Pauly, D., Ingles, J., \& Neal, R. (1984). Application to shrimp stocks of objective methods for the estimation of growth, mortality and recruitment related parameters from length frequency data (ELEFAN I and II). In: Penaeid shrimp - their biology and management, (p. 220-234). Fishing News Book Limited. FarnhamSurrey-England.

Purwanto \& Nugroho, D. (2010). Tingkat optimal pemanfaatan stok udang, ikan demersal dan pelagis kecil di Laut Arafura. J.Lit.Perik.Ind. 16(4), 311-312.

Setyohadi, D., Nugroho, D., Lelono, T.J., Wiadnya, D.G.R., $\&$ Martinus (1999). Biologi dan distribusi sumber daya udang penaeid berdasarkan hasil tangkapan di Selat Madura. Laporan Penelitian Litbang Pertanian, 5061.

Sparre, P., \& Venema, S.C. (1998). Introduction to tropical fish stock assessment. Part I Manual. FAO Fish. Tech Pap. No. 306/1.

Suman, A. (2004). Pola pemanfaatan sumber daya udang dogol (Metapenaeus ensis de Haan) di perairan Cilacap dan sekitarnya. Disertasi. Sekolah Pascasarjana IPB, Bogor.

Tirtadanu \& Ernawati, T. (2016). Kajian biologi udang jerbung (Penaeus merguiensis De Mann, 1888) di perairan utara Jawa Tengah. Bawal Widya Riset Perikanan. 8(2), 109-116. 